\title{
Changing on Patient-Centred Attitudes on Same Students Group: A Qualitative Study
}

\section{Tontus $\mathrm{HO}^{*}$ and Nebioglu S}

Public Hospital Administration of Turkey, TKHK, Balgat, Ankara, Turkey

*Corresponding author: Tontus HO, Public Hospital Administration of Turkey, TKHK, Balgat, Ankara, Turkey, Tel: 905425575272; E-mail: otontus@hotmail.co.uk

Received date: February 5, 2018; Accepted date: February 12, 2018; Published date: February 15, 2018

Copyright: ( 2018 Tontus $\mathrm{HO}$, et al. This is an open-access article distributed under the terms of the Creative Commons Attribution License, which permits unrestricted use, distribution, and reproduction in any medium, provided the original author and source are credited.

\begin{abstract}
Objective: Study aimed to clarify the effect of educational activities on same students in their pre-med students and medical students standing point about patient centred care.

Methods: The PPOS questionnaire used to examine patient-centredness and has been used in pre-med student and medical student samples. We surveyed students in their first month in undergraduate medical education following their enrolment in 2010. Three years later in 2013-2014 educational year same group included to same questionnaire, when they are 4th year students. Same 128 students filled questionnaire forms in two different years. The survey utilized the patients practitioners orientation scale (PPOS) to measure students' changing attitudes.

Results: $59 \%$ of respondents were female and mean age was 18.52 in their 1 st year. In total PPOS scores were 55.58 for Year 4 students and 62.41 for Year 1 students. We found that sharing and caring domains scores lowered when students finished their basic medical science education including empathy, communication and ethics lectures.

Conclusion: Despite encouraging patient-centred attitudes of undergraduate medical students by curricular models, our findings showed that in their further level, students became less patient centred. Depending on respondents' score, curriculum organisers should re-check their curricular aim and educational program or activities. Feedback in medical education can be accepted as "specific information about the students' perception and attitudes". These findings give great information concerning effectiveness of program on specific areas with the clues to improve the program' performance".
\end{abstract}

Keywords: Attitude; Curriculum; Doctor-patient relations; Patient centred care; PPOS; Provider centred care

\section{Introduction}

Patient-centered care (PCC) is a key element of quality of healthcare. This approach focuses partnerships in healthcare service between patients, patients' relatives and healthcare professionals. This recognises patients' preferences and promotes flexibility in health care and encourages moving beyond the provider or doctor centred approach. The doctor-patient relationship (DPR) is essential to operate best medical services and has been shown to affect patient satisfaction in many articles $[1,2]$. Since the 1950s, DPR has been studied with many models, but the two main models have been the paternalistic model and the participatory model [3]. There is increasing interest among researchers and practitioners to better understand the extent of patient-centred care. In participatory model, patients take an active role in their health care service and medical decision [4]. In despite of popularity of the idea there is little agreement as to its meaning [5]. In one hand, PCC is the aspect of DPR that consider patients' preferences, reactions and emotions; and in other hand "doctor centred care" is the other aspect of DPR that consider doctors' preferences, reactions and emotions. Beyond these two models there is another DPR model that is "provider centred care" that takes into account medical centres' or hospitals' preferences, concerns and profits. Since many years, undergraduate medical curriculum developers have accepted the significance of PCC by developing different courses and electives to teach communication skills, humanistic conducts and professional values to medical students [6]. Such as Ondokuz Mayis University Medical School (OMU/MS) most of the institutions are supposed to foster positive attitudes towards DPR. However, running programme and educational philosophy may act as an obstacle to medical teachers' attempts to satisfactory PCC education. We designed this study to depict and evaluate students' changing attitudes towards DPR, in Year 1 and in Year 4 with the same students group.

We aimed to determine the effect of educational programs on medical students whether the patient-centeredness became stronger or eroded.

\section{Methods}

We assessed attitudes towards DPR among same student group in their first year (Y1) and fourth-year (Y4). Survey conducted on a large Turkish medical faculty which having over 1250 undergraduate medical students and 360 residents. Medical educations in Turkey as in most European countries run a 6-year programme. Our undergraduate medical study education has a 6-year compulsory curriculum is divided into 3 years mainly basic medical sciences education with skills laboratory, 2 years clinical clerkship and 1 year internship curricula.

Previously validated 18 items self-administered instrument, "The Patient-Practitioner Orientation Scale (PPOS)" used for measurements of attitudes toward DPR [7]. Participation was voluntary. The individuals who participated in research were requested 
Page 2 of 4

to scale their agreement/disagreement on each item of questionnaire as Likert Type Scale scored between 1 (strongly agree) and 6 (strongly disagree). There are 3 items (item 9, 13, and 17) scored reversely. We analysed each items' scores between 1 (more doctor-centred) and 6 (more patient centred). PPOS originally aimed to be administered to health related individuals (patients, students or physicians). It measures attitudes toward DPR with two related dimensions, which are 'sharing' and 'caring' [2]. Items 1, 4, 5, 8, 9, 10, 12, 15 and 18 related with sharing domain that verifying the scale of respondent' standing point about their feeling on "authority and control must be shared between patient and doctor". Remaining nine items $(2,3,6,7,11,13$, 14,16 and 17) considered as caring aspect that verifying the scale to which the participants cares about the importance of warmth, affection and support in DPR. The overall PPOS score calculated as total scores and the mean scores of 18 items. We collected additional demographic data from all respondents.

Paper based survey form used for data collection. Students completed survey during their first year and fourth year. Survey forms dealt out during orientation week of Y1 students before they met any medical lectures (as accepted pre-med students). 167 of 196 (85.20\%) students returned filled forms. When same students' group finished their basic medical science education in their fourth year, students' survey forms dropped off to students' affair office for participation with an attached note on it "only for Year 4 students which enrolled 2010" and $128(81.53 \%)$ of 157 Y4 eligible students are filled the form. In the beginning of the fourth year of undergraduate medical education interaction with patients is not established yet. And because of that we accepted Y4 students to the survey.

\section{Results}

In total $295(167$ Y1 + 128 Y4) filled PPOS survey forms completed. Demographics of respondents by groups and gender are presented in Table 1. The study group included 128 students who completed both surveys in two different educational levels. Respondents indicated their gender as male or female, and they also were asked to indicate their current age. As shown on table; 75 (58.59\%) of 128 respondents were female and average age of Y1 students and Y4 students was 18.52 (SD 0.83 ) and 21.52 (SD 0.83) respectively.

\begin{tabular}{|l|l|l|l|l|}
\hline & Y1 Student & & Y4 Student & \\
\cline { 2 - 5 } & & & $\mathbf{n}$ & $\%$ \\
\hline Female & 75 & $58.59 \%$ & 75 & $58.59 \%$ \\
\hline Male & 53 & $41.41 \%$ & 53 & $41.41 \%$ \\
\hline & Year & SD & Year & SD \\
\hline Mean Age & 18.52 & 0.83 & 21.52 & 0.83 \\
\hline
\end{tabular}

Table 1: Demographic data by groups.

The mean scores and SDs for responses to the items comprising the PPOS are shown in Table 2. In our study, items' PPOS scores ranged from 1.96 (item 15) to 5.22 (item 11) in Y1 and from 1.41 (item 14) to 5.30 (item 13) in Y4. The PPOS mean scores derived from the collected data as shown in Table 2 was 3.47 for Y1 and 3.09 Y4 groups. We found that Y4 students were significantly associated with lower mean PPOS score when comparing with Y1 student $(\mathrm{p}<0.001)$. All scores including sharing domain mean, caring domain mean and mean PPOS were higher for Y1 students group (Table 3).

Students who enrolled but they didn't start to medical education in a professional manner stand on patients' point of view when compared students who they started to clerkship period. Y4 students, which they are newly educated individuals that their medical curriculum consists of medical humanities lectures such as ethics, communication, empathy with lower PPOS scores, are need to be evaluated by the educators and curriculum designers.

The question is; why patient centred high school graduate individuals shift to doctor centred students while their medical education period? In total PPOS scores were 55.58 for Y4 students and 62.41 for Y1 students. All PPOS scores summarised on Table 3. Y1 students' score were more significantly associated with patient-centred attitudes when compared with Y4.

\begin{tabular}{|c|c|c|c|c|c|}
\hline \multirow[b]{2}{*}{ ITEMS } & \multicolumn{2}{|c|}{ Year 1 Students } & \multicolumn{2}{|c|}{ Year 4 Students } & \multirow[t]{2}{*}{ p value } \\
\hline & Mean & SD & Mean & SD & \\
\hline 1. The doctor is the one who should decide what gets talked about during a visit & 2.98 & 1.33 & 1.93 & 0.73 & $<0,001$ \\
\hline 2. If health care is less personal these days, this is a small price to pay for medical advances & 4.43 & 1.47 & 3.68 & 1.37 & $<0,001$ \\
\hline 3. The most important part of the standard medical visit is the physical exam & 2.92 & 1.00 & 3.20 & 1.28 & $<0,047$ \\
\hline 4. It is often best for patients if they do not have a full explanation of their medical condition & 2.10 & 1.03 & 1.88 & 0.68 & $<0,036$ \\
\hline 5. Patients should rely on their doctors' knowledge and not try to find out their conditions on their own & 2.59 & 1.60 & 1.98 & 0.88 & $<0,001$ \\
\hline $\begin{array}{l}\text { 6. When doctors ask a lot of questions about a patient's background, they are prying too much into } \\
\text { personal matters }\end{array}$ & 3.23 & 1.12 & 2.04 & 0.78 & $<0,001$ \\
\hline $\begin{array}{l}\text { 7. If doctors are truly good at diagnosis and treatment, the way they relate to patients is not that } \\
\text { important }\end{array}$ & 4.95 & 1.22 & 4.43 & 1.21 & $<0,001$ \\
\hline 8. Many patients continue asking questions even though they are not learning anything new & 3.03 & 1.06 & 2.31 & 0.93 & $<0,001$ \\
\hline
\end{tabular}




\begin{tabular}{|c|c|c|c|c|c|}
\hline 9. Patients should be treated as if they were partners with the doctor, equal in power and status & 5.20 & 1.12 & 4.79 & 1.49 & $<0,012$ \\
\hline 10. Patients generally want reassurance rather than information about their health & 2.26 & 1.00 & 2.20 & 0.72 & 0,583 \\
\hline 11. If a doctor mainly relies on being open and warm, the doctor will not have a lot of success & 5.22 & 1.06 & 3.38 & 1.57 & $<0,001$ \\
\hline $\begin{array}{l}\text { 12. When patients disagree with their doctor, this is a sign that the doctor does not have the patient's } \\
\text { respect and trust }\end{array}$ & 3.38 & 1.45 & 2.70 & 1.15 & $<0,001$ \\
\hline 13. A treatment plan cannot succeed if it is in conflict with a patient's lifestyle or values & 4.39 & 1.29 & 5.30 & 0.69 & $<0,001$ \\
\hline 14. Most patients want to get in and out of the doctor's office as quickly as possible & 2.06 & 1.27 & 1.41 & 0.63 & $<0,001$ \\
\hline 15. The patient must always be aware that the doctor is in charge & 1.96 & 1.16 & 1.73 & 0.88 & 0,071 \\
\hline $\begin{array}{l}\text { 16. It is not that important to know a patient's culture and background in order to treat the person's } \\
\text { illness }\end{array}$ & 3.86 & 1.48 & 5.00 & 1.25 & $<0,001$ \\
\hline 17. A friendly manner is a major ingredient in the doctor's treatment of the patient & 5.17 & 1.07 & 5.27 & 1.42 & 0,529 \\
\hline 18. When patients find out medical information on their own, this usually confuses more than it helps & 2.68 & 1.27 & 2.38 & 1.16 & 0,056 \\
\hline Total Score & 62.41 & & 55.58 & & \\
\hline Meean PPOS Score & 3.47 & & 3.09 & & $<0.001$ \\
\hline
\end{tabular}

Table 2: Students responses to survey items.

When comparing total PPOS, sharing and caring by male and female respondents in Y1 and Y4 groups we didn't find any statistically important differences depending on sex. Following this finding we tried to find differences by sex between $\mathrm{Y} 1$ and $\mathrm{Y} 4$. We found statistically proven shift from patients centredness to more doctor centredness in both sexes' PPOS score in all three domains (Table 4).

\begin{tabular}{|l|l|l|l|l|l|}
\hline \multirow{2}{*}{ Variables } & Y1 Students & & Y4 Students & & \\
\cline { 2 - 6 } & Score & Mean & Score & Mean & p value \\
\hline Sharing & 26.18 & 2.91 & 21.88 & 2.43 & $<0.001$ \\
\hline Caring & 36.23 & 4.03 & 33.7 & 3.74 & $<0.001$ \\
\hline Total & 62.41 & 3.47 & 55.58 & 3.09 & $<0.001$ \\
\hline
\end{tabular}

Table 3: Mean patient-practitioner orientation scale, sharing and caring scores by groups.

All 18 items compared by one by for Y1 and Y4 students and we found that changes on items $10,15,17$ and 18 statistically unimportant. Remaining 14 items dramatically shifted away from patients' side to practitioners' side (Table 2).

\begin{tabular}{|l|l|l|l|l|l|l|}
\hline \multirow{2}{*}{} & \multicolumn{5}{|l|}{ Male } & \multicolumn{3}{l|}{ Female } \\
\cline { 2 - 7 } & Y1 & Y4 & p value & Y1 & Y4 & p value \\
\hline Sharing & 2.87 & 2.49 & $<0.001$ & 2.93 & 2.39 & $<0.001$ \\
\hline Caring & 3.99 & 3.72 & $<0.001$ & 4.05 & 3.76 & $<0.001$ \\
\hline All & 3.43 & 3.11 & $<0.001$ & 3.49 & 3.07 & $<0.001$ \\
\hline & Year 1 & \multicolumn{5}{|l}{ Year 4 } \\
\hline
\end{tabular}

\begin{tabular}{|l|l|l|l|l|l|l|}
\hline & Male & Female & p value & Male & Female & p value \\
\hline Sharing & 2.87 & 2.93 & $>0.05$ & 2.49 & 2.39 & $>0.05$ \\
\hline Caring & 3.99 & 4.05 & $>0.05$ & 3.72 & 3.76 & $>0.05$ \\
\hline All & 3.43 & 3.49 & $>0.05$ & 3.11 & 3.07 & $>0.05$ \\
\hline
\end{tabular}

Table 4: Students sex related analysis of response.

Four of the items changed through PCC during the undergraduate education from Y1 to Y4. These are item 3, 13, 16 and 17 that are all belongs to caring subdomains. Except item 17 all differences are statistically meaningful. The students care about the affection, value of warmth and support in DPR more patient centred in these 4 items in their further years in medical schools.

Although three years of educational activities which including patients centred lectures and small group discussion, students perception shifted through doctor centred approach.

\section{Conclusion}

This is the first PPOS study in medical education that compared same student groups attitude change. We don't have any previous published data to compare Turkish students' behavioural changes. We found sharing scores lower than caring scores in both year students. As our results, many researchers reported that healthcare professionals have lower 'sharing' but higher 'caring' scores on the same groups $[8,9]$.

In theory, medical school is supposed to foster positive attitudes towards DPR in the favour of PCC. But in practice, loss of idealism, diseases-centred media and investor pressure together with burden of performance based payment systems dissuade healthcare professionals. In 2002-2003 educational year, our curriculum supplemented by new 
courses in the manner of PCC such as ethics, empathy, communication, patients right, breaking bad news.

In 2012, perhaps the most widely scrutinised area of the economy in USA (as well as Europa) was the healthcare industry. Politicians, strategy analysts, academics, and the public share concerns about the state of healthcare worldwide [10]. However, each of these has a different perspective 10. Such as these stakeholders, students also have changing demands over the time about healthcare and patient's needs.

This study result can be accepted as feedback in medical education about "information of students' perception and attitudes", which gives great information concerning effectiveness of program on specific areas with the clues to improving required areas of the program. We can use our survey results as a criticism for curriculum designers [11].

The data collected in this survey and the effects of its analysis are important. Krupat et al. 12 noted in their publication as "a patientcentred positioning translates into adaptability to patient requirements, lecturers do not need to recommend a specific tactic or educate a certain set of behavioural cores". They also point out need to provoke physicians to being courteous in different styles of patient sidedness including sharing and caring subdomains [12].

Survey related feedback indicates shifting attitudes of students in patient centeredness is straightforward and this is not a desired result of educational program.

In theory, medical students and physicians recognise significance to empathy in practice. In their study, Mahoney and colleagues have indicated that the reason for the decline in empathy scores during the course of medical education cannot be understood. An improved program and activities are needed in undergraduate medical education about the patient's centred care [13].

PPOS survey results lead us to rethink on educational activities and role modelling. On the other hand, these results can be perceived as negative feedbacks for curriculum designers and deanery to develop better programs. More (and focused) studies are required to identify evidence to evaluate effect of curriculum on PCC. This is a difficult area to research. There are needs for more randomised studies on behavioural changing following educational activities. There is, however, statistically meaningful evidence that our students were more patient's centred perspective before they started medical education because they were patients or patient relatives. PCC is respecting and responding to the needs of patients as a key component of high-quality care. Student's achievement on communication in medical school program and their skill progress are assessed and evaluated by complex exams. In our educational program, students are given feedback on their communication skills in their pre-clinical education period (first 3 years). Unfortunately, students are rarely taken into account of their communication skills education and they prefer to focus on major courses such as anatomy, histology and microbiology etc. This lack of attention causing to shift from PCC.

As a result of this research, we can confess that; our program "somehow" leads our students to have a doctor centred care opinion.

\section{References}

1. Simpson M, Buckman R, Stewart M, Maguire P, Lipkin M, et al. (1991) Doctor-patient communication: The Toronto consensus statement. BMJ 303: $1385-7$.

2. Haidet P, Dains JE, Paterniti DA, Hechtel L, Chang T, et al. (2002) Medical student attitudes toward DPR. Med Educ 36: 568-574.

3. Cvengros JA, Christensen AJ, Hillis SL, Rosenthal GE (2007) Patient and physician attitudes in the health care context: attitudinal symmetry predicts patient satisfaction and adherence. Ann Behav Med 33: 262-268.

4. Robison WL, Pritchard MS (1979) Medical responsibility: Paternalism, informed consent, and euthanasia. Clifton, NJ: Humana, Childress JF: Who Should Decide? Paternalism in Health Care. New York: Oxford University Press.

5. Mead N, Bower P (2000) Patient-centredness: A conceptual framework and review of the empirical literature. Soc Sci Med 51: 1087-1110.

6. Schmidt H (1998) Integrating the teaching of basic sciences, clinical sciences, and biopsychosocial issues. Academic Med 73: S24-31.

7. Krupat E, Putnam SM, Yeager C (1996) The fit between doctors and patients: Can it be measured? J General Intern Med 11: 134.

8. Lee KH, Seow A, Luo N, Koh D (2008) Attitudes towards DPR: A prospective study in an Asian medical school. Med Educ 42: 1092-1099.

9. Tsimtsiou Z, Kerasidou O, Efstathiou N, Papaharitou S, Hatzimouratidis K, et al. (2007) Medical students' attitudes toward patient-centred care: A longitudinal survey. Med Educ 41: 146-153.

10. Detsky AS (2011) What patients really want from health care; JAMA. 306: 2500-2501.

11. Krupat E, Bell RA, Kravitz RL, Thom D Azari R (2001) When physicians and patients think alike: patient-centered beliefs and their impact on satisfaction and trust. J Fam Pract 50: 1057-1062.

12. Krupat E, Rosenkranz SL, Yeager CM, Barnard K, Putnam SM (2000) The practice orientations of physicians and patients: The effect of doctorpatient congruence on satisfaction. Patient Educ Couns 39: 49-59.

13. Mahoney S, Sladek RM, Neild T (2016)A longitudinal study of empathy in pre-clinical and clinical medical students and clinical supervisors. BMC Med Educ 16: 270. 